\title{
TRIBOLOGICAL PERFORMANCE OF DIAMOND AND DIAMONDLIKE CARBON FILMS AT ELEVATED TEMPERATURES
}

A. Erdemir (Member, STLE) and G. R. Fenske

Tribology Section

Energy Technology Division

Argonne National Laboratory

Argonne, II 60439
TECEIVED

APR 171996

OSTI

September 1995

The submitted manuscript has been authored by a

contractor of the U. S. Government under contract No.

W-31-109-ENG-38. Accordingly, the U. S. Government

retains a nonexclusive, royalty-free license to publish or

reproduce the published form of this contribution or

allow others to do so. for U.S. Government purposes.

For presentation at 1996 Annual Meeting of the Society of Tribologists and Lubrication Engineering, May 19-23, 1996, Cincinnati, OH

*Work supported by the U.S. Department of Energy, under Contract W-31-109-Eng-38. 


\section{DISCLAIMER}

Portions of this document may be illegible in electronic image products. Images are produced from the best available original document. 


\title{
TRIBOLOGICAL PERFORMANCE OF DIAMOND AND DIAMONDLIKE CARBON FILMS AT ELEVATED TEMPERATURES*
}

\author{
A. Erdemir (Member, STLE) and G. R. Fenske \\ Tribology Section \\ Energy Technology Division \\ Argonne National Laboratory \\ Argonne, IL 60439
}

\section{ABSTRACT}

In this study, we investigated the tribological performance of diamond and diamondlike carbon (DLC) films as a function of ambient temperature. Both films were deposited on silicon carbide (SiC) by microwave plasma chemical vapor deposition and ion-beam deposition processes. Tribological tests were performed on a reciprocating wear machine in open air (20 to $30 \%$ relative humidity) and under a $10-\mathrm{N}$ load using $\mathrm{SiC}$ pins. For the test conditions explored, the steady-state friction coefficients of test pairs without a diamond or DLC film were 0.7 to 0.9 and the average wear rates of pins were $10^{-5}$ to $10^{-7} \mathrm{~mm}^{3} / \mathrm{N}$.m, depending on ambient temperature. DLC films reduced the steady-state friction coefficients of test pairs by factors of 3 to 5 and the wear rates of pins by two to three orders of magnitude. Low friction coefficients were also obtained with the diamond films, but wear rates of the counterface pins were high due to the very abrasive nature of these films. The wear of SiC disks coated with either diamond or DLC films was virtually unmeasurable while the wear of uncoated disks was substantial. Test results showed that the DLC films could afford low friction up to about $300^{\circ} \mathrm{C}$. At higher temperatures, the DLC films became graphitized and were removed from the surface. The diamond films could withstand much higher temperatures, but their tribological behavior degraded. Raman spectroscopy and scanning electron microscopy were used to elucidate the friction and wear mechanisms of both films at high temperatures.

Key Words: Diamond and diamondlike carbon films, solid lubrication, high-temperature friction and wear. 


\section{INTRODUCTION}

Extreme hardness, high chemical stability, and low friction character of diamond and diamond-like carbon (DLC) films make them good candidates for a wide range of tribological applications, including bearings, gears, seals, and metal-cutting and forming tools [1-3]. Unlike the very popular nitride and carbide coatings (e.g., TiN and $\mathrm{TiC}$ ) which function more effectively under oil-lubricated sliding-contact conditions [4,5], smooth diamond and DLC coatings provide low friction and high wear resistance to most sliding surfaces even without lubrication [6-16]. Furthermore, these coatings are significantly harder and much stiffer than most carbides and nitrides.

Previous research has demonstrated that the friction and wear performance of both diamond and DLC coatings can be very sensitive to surface finish [17-19], environment $[11,14,15]$, and ambient temperature $[7,14,15,20,21]$. According to Hayward and coworkers [17-19], the surface roughness of diamond coatings could have a substantial impact on friction and wear. In general, rougher diamond films give rise to higher friction and wear. The testing environment was also found to influence the tribological performance of these coatings $[11,12,14,15]$. For example, the friction coefficients of diamond and DLC films against various ceramic balls were reported to be about 0.04 and 0.02 , respectively, in dry $\mathrm{N}_{2}$, whereas in humid air these friction values increased by factors of 3 to 5 [12]. Tests by Dugger et al. [22] showed that the friction coefficients of diamond films could be very high in ultrahigh vacuum. They attributed high friction to the removal of surface adsorbates during sliding. Bleeding air into the test chamber reduced friction by more than one order of magnitude.

At elevated temperatures, the friction and wear performance of diamond and DLC films deteriorates substantially. At temperatures $>300^{\circ} \mathrm{C}$, the DLC films became more graphitelike $[7,14,20]$ and delaminated from the sliding surfaces, thus losing their effectiveness. As for the diamond films, Kohzaki et al. [21] reported friction coefficients of 0.8 at $600^{\circ} \mathrm{C}$ for $\mathrm{SiC}$ balls sliding against the diamond films. In a series of recent papers, Gardos et al. $[15,23,24]$ showed that the friction coefficients of polycrystalline diamond against itself are fairly low in mild vacuum 
and at temperatures up to $500^{\circ} \mathrm{C}$. At higher temperatures, Gardos et al. noted unexpected increases in friction and attributed such phenomena to the desorption of surface adsorbates that are known to passivate the dangling bonds of diamond surfaces.

In this paper, we present the tribological performance of diamond and DLC films on a comparative manner at temperatures up to $400^{\circ} \mathrm{C}$. The DLC coatings performed reasonably well up to $300^{\circ} \mathrm{C}$, but became graphitized at much higher temperatures. As for the diamond coatings, they could endure higher temperatures, but their tribological performance was not very good.

\section{EXPERIMENTAL DETAILS}

\section{Test Materials}

The pins and flats used in this study were sintered $\mathrm{SiC}$, obtained from a commerical source [25]. The flat samples were in rectangular shape $(38.1 \times 50.8 \times 4.2 \mathrm{~mm})$ and had a surface roughness of about $0.03 \mu \mathrm{m}$ center-line-average (CLA). SiC pins were $15 \mathrm{~mm}$ long and 8- $\mathrm{mm}$ in diameter. One end of each pin was rounded to a radius of curvature of $127 \mathrm{~mm}$, and pin surface finish was $\approx 0.03 \mu \mathrm{m}$ CLA. All specimens were ultrasonically cleaned sequentially in trichlorethylene, acetone, and methanol for 10 minutes each, then dried in an oven at $110^{\circ} \mathrm{C}$ for $20 \mathrm{~min}$.

\section{Deposition of Diamond and DLC Coatings}

Thin DLC films ( $\approx 1.5 \mu \mathrm{m}$ thick) were ion-beam deposited on $\mathrm{SiC}$ at room temperature in a vacuum chamber equipped with a broad-beam ion source. A short description of the procedures used during the preparation of DLC coatings is given below, while more detailed description can be found in Refs. 7 and 10.

First, the $\mathrm{SiC}$ substrates were positioned directly below the ion source and sputter-cleaned with 1 $\mathrm{keV}, 2.5 \mathrm{~mA} / \mathrm{cm}^{2}$ Ar-ion beam for $\approx 3-5 \mathrm{~min}$. Argon gas used for sputter-cleaning was fed through 
the cylindrical ion source of the broad-beam system and ionized by energetic electrons that were produced by a hot filament wire. At the conclusion of the sputter-cleaning step, the DLC deposition was begun by switching from argon to methane, the carbon source. The methane was fed through the same cylindrical ion source and was ionized by energetic electrons emitted by the hot filament wire. Operating conditions were adjusted to give an ion beam with an acceleration energy of $450 \mathrm{eV}$ and current density of $\approx 2.5 \mathrm{~mA} / \mathrm{cm}^{2}$. Under these operating conditions, the deposition rate was $\approx 3 \mu \mathrm{m} / \mathrm{hr}$. Deposition was continued until a $1.5-\mu \mathrm{m}$-thick DLC film was obtained. Because of the methane as carbon source, the DLC films produced here contained about 23 at.\% hydrogen and had a Vickers hardness value of about $17 \mathrm{GPa}$.

The diamond films used in these study were prepared in a microwave-plasma-assisted chemicalvapor-deposition reactor. Prior to deposition, the optically polished $\mathrm{SiC}$ substrates were given a final dry vibratory polishing treatment with $0.1 \mu \mathrm{m}$ diamond particles to enhance film nucleation and promote growth of a uniform, continuous diamond film. The films were deposited at substrate temperatures of approximately 900 to $950^{\circ} \mathrm{C}$. During the initial stages of deposition, the surfaces were cleaned in pure $\mathrm{H}_{2}$ plasma at a flow rate of $100 \mathrm{sccm}$ for approximately $15 \mathrm{~min}$ at 40 torr and a forward microwave power of $1250 \mathrm{~W}$. After $15 \mathrm{~min}$ of surface cleaning, deposition was initiated by increasing the flow of methane to $2 \mathrm{sccm}$ for the remainder of the run. The SiC samples were coated for 30 and 60 hours resulting in film thicknesses of $\approx 15$ and $\approx 30$ $\mu \mathrm{m}$, respectively.

\section{Tribological Tests}

The tribological tests were conducted on a reciprocating wear test rig in which the pin specimen was firmly secured on a holder and drawn back and forth across the stationary flat. Frequency and stroke length were $1 \mathrm{~Hz}$ and $25 \mathrm{~mm}$, respectively, giving an average sliding velocity of $0.05 \mathrm{~m} / \mathrm{s}$. Each test was run for 4000 cycles or 8000 passes, which amounts to sliding distance of $\approx 200 \mathrm{~m}$. The dead weight on top of the pin specimen sliding against the flat was $10 \mathrm{~N}$, which created a mean Hertzian pressure of $\approx 125 \mathrm{MPa}$. Room humidity ranged between 20 to $30 \%$ during the tests 
at room temperature (e.g., $23^{\circ} \mathrm{C}$ ). Further details of this test rig are given in Ref. 4.

For tests at high temperatures, electrical cartridge heaters were inserted into the upper and lower stainless steel plates that housed the pin and flat specimens. Friction force, which was monitored by strain-gauge transducer, was recorded continuously throughout the tests. The wear volume measurement of each pin specimen was based on the radius (R) of the hemispherical end of pins, and the microscopic determination of the wear scar radius $(r)$, which were subsequently converted into wear volume $(V)$ by the mathematical expression $\left\{V=\left(\pi r^{4}\right) /(4 R)\right\}$ suggested in $\operatorname{Ref}$. [26]. The wear of flat specimens was assessed from the three-dimensional traces of surface profiles across the wear tracks. For better accuracy and reproducibility, duplicate tests were run at each temperature, mean values of friction coefficients and wear rates are reported. The wear tracks and the scars, as well as the wear-debris particles, were examined by scanning electron microscopy (SEM) and Raman spectroscopy operating with a HeNe laser having a wavelength of $632.8 \mathrm{~nm}$ with an output power of $25 \mathrm{~mW}$ over a spot size of $2 \mu \mathrm{m}$.

\section{RESULTS}

\section{Film Microstructure and Chemistry}

The cross-sectional SEM images of the DLC and diamond films are shown in Fig. 1. As is clear from Fig. 1a, the structure of DLC film appears very dense and featureless, whereas the diamond film (Fig. 1b) is highly faceted and composed of coarse grains. Figure 2 reveals that the surface topography of this diamond film is very rough. Figure 3 shows the laser Raman spectra of both films. The spectrum of diamond film shows a sharp Raman band at $1332 \mathrm{~cm}^{-1}$, which is characteristic of these films. It also features a broad peak at around $1520 \mathrm{~cm}^{-1}$ which may be due to non-diamond precursors $[27,28]$.

The Raman spectrum of DLC is very different from that of diamond. It shows a very broad peak centered at $1520 \mathrm{~cm}^{-1}$ and a shouldered peak at around $1345 \mathrm{~cm}^{-1}$. In general, both peaks are 
typical of most carbon materials classified as DLC [28-30].

\section{Friction and Wear}

Figure 4 shows the friction coefficients of $\mathrm{SiC}$ pins during sliding against itself and against diamond and DLC coatings at different temperatures. As is evident, the friction coefficients of $\mathrm{SiC}$ against itself are quite high and vary significantly with temperature. Up to $200^{\circ} \mathrm{C}$, their friction coefficients range from 0.8 to 0.9 , although a slight decrease occurs during tests at 300 and $400^{\circ} \mathrm{C}$. The friction coefficients of $\mathrm{SiC}$ pins against diamond film is about 0.4 at room temperature, but decreases to $0.3-0.25$ at $300^{\circ} \mathrm{C}$. At $400^{\circ} \mathrm{C}$, the friction coefficient increases to 0.5. The friction coefficients of $\mathrm{SiC}$ pins against $\mathrm{DLC}$-coated $\mathrm{SiC}$ flats fluctuate between 0.2 and 0.25 during tests at temperatures from $23^{\circ}$ to $400^{\circ} \mathrm{C}$. They appear to be relatively insensitive to increasing temperature. The asterisks along the friction coefficient at $400^{\circ} \mathrm{C}$ means that the 0.2 friction coefficient could be maintained for the first 1500 sliding cycles. After that, friction increased to 0.6 , and microscopic examination of the sliding surface after the test revealed that the film was largely removed from the surface, as shown in Fig. 5.

Figure 6 shows the average specific wear rates of $\mathrm{SiC}$ pins sliding against itself and diamond and DLC-coated $\mathrm{SiC}$ flats at different temperatures. The wear rate of $\mathrm{SiC}$ pins against $\mathrm{SiC}$ is about 3.6 $\mathrm{X} 10^{-7} \mathrm{~mm}^{3} \mathrm{~N} \cdot \mathrm{m}$ at room temperature, but increases markedly at higher temperatures. At room temperature, the wear rates of $\mathrm{SiC}$ pins sliding against the diamond-coated $\mathrm{SiC}$ flats were 6 times higher than those of the pins slid against the uncoated $\mathrm{SiC}$ flats. At elevated temperatures, pin wear rates increased substantially and in fact became comparable to those of the pins slid against the uncoated $\mathrm{SiC}$ flats. However, wear rates of $\mathrm{SiC}$ pins sliding against the DLC-coated $\mathrm{SiC}$ flats were very low, ranging from $1.2 \times 10^{-8} \mathrm{~mm}^{3} / \mathrm{N} . \mathrm{m}$ at $200^{\circ} \mathrm{C}$ to about $2.2 \times 10^{-8} \mathrm{~mm}^{3} / \mathrm{N} . \mathrm{m}$ at room temperature. These values are two to three orders of magnitude lower than the wear rates of balls slid against the uncoated disks. Photomicrographs in Fig. 7 compare the actual sizes of wear scars formed on $\mathrm{SiC}$ pins during tests at room temperature. As is clear, the largest wear scar was seen on a pin slid against the diamond-coated $\mathrm{SiC}$ flat (Fig. 7a), whereas the smallest scar was found 
on a pin slid against the DLC-coated SiC flat (Fig. 7b). The wear scar formed on the pin slid against the bare $\mathrm{SiC}$ flat was much smaller than that formed against the diamond film, but significantly larger than that formed against DLC film (Fig. 7c).

SEM microscopy of the worn surfaces of $\mathrm{SiC}$ pins and uncoated $\mathrm{SiC}$ flats revealed that grain pullout and microfracture were the dominant wear modes for these samples (see Fig. 8). In the case of $\mathrm{SiC}$ pins slid against the diamond films, the wear was mostly dominated by microcutting (see Fig. 7a). The wear of pins sliding against the DLC-coated flats was in the form of fine polishing.

Three-dimensional surface maps in Fig. 9 compare the extent of wear damage occurred on bare, diamond, and DLC-coated SiC flats. As is clear, the extent of wear on the uncoated flat is rather significant. Wear of the DLC-coated SiC flats was hard to discern. Using a surface profilometer, we could not reliably detect measurable amounts of wear losses on the diamond and DLC-coated flats. Further SEM examinations revealed that wear was confined essentially to the sharp asperity tips of diamond film. Also loose debris particles filled in the valleys between sharp crystal facets of diamond films and resulted in a smooth wear track (see Fig. 10). The DLC films were still intact after sliding tests at temperatures to $300^{\circ} \mathrm{C}$. However, as mentioned above, during tests at $400^{\circ} \mathrm{C}$, the DLC film delaminated and the wear of $\mathrm{SiC}$ pin (see Fig. 6) became significant.

\section{DISCUSSION: FRICTION}

\section{SiC/SiC Test Pairs}

The high friction coefficients of the $\mathrm{SiC} / \mathrm{SiC}$ test pairs (0.7-0.9) are typical for this ceramic under dry sliding conditions and comparable to values reported elsewhere [31]. The slight decrease in friction with increasing temperature may be due to the formation of a tribochemical film that provides marginal lubrication. Also, as reported by Buckley and Miyoshi limited amounts of 
carbon are released from the $\mathrm{SiC}$ material during dynamic sliding at elevated temperatures, and this carbon may provide marginal lubrication [32]. Overall, the range of friction coefficients for the $\mathrm{SiC} / \mathrm{SiC}$ pairs reported here is quite consistent with the previous data reported in Refs. 31 and 32.

\section{SiC/DLC-SiC Test Pairs}

The generally low friction coefficients of pairs with a DLC film are due largely to the very inert nature and easy shear character of DLC surfaces. Compared to the very low friction coefficients (0.005-0.05) in vacuum, dry $\mathrm{N}_{2}$ or $\operatorname{Ar}[11,13,14]$, the coefficients reported in Fig. 4 are significantly higher. This is largely because of the fairly high humidity (e.g., 20-30\%) during our friction tests. Overall, these friction coefficients are in keeping with those reported for DLC films in humid test environments $[6,7,9,11,14]$. One explanation given for the relatively higher friction coefficients in humid environments was that the real contact areas of sliding surfaces may became saturated with water molecules, and this exerts additional bonds across the contact interfaces, thus causing higher friction [14].

Figure 4 shows that the friction coefficients of SiC/DLC-coated SiC pairs did not significantly change during tests at temperatures up to $300^{\circ} \mathrm{C}$. However, at $400^{\circ} \mathrm{C}$, low friction could be maintained for the first 1500 cycles, after which the friction coefficient increased sharply to $\approx 0.6$. This was due to the removal of DLC from the wear track (see Fig. 5). Laser Raman spectroscopy of this wear track (see Fig. 11) revealed that the remnants of the DLC film had essentially transformed to graphite. The peak positions of the graphitized DLC overlap with the D and G bands of the crystalline graphite. Therefore, the short lifetime of DLC at $400^{\circ} \mathrm{C}$ must have been due to graphitization. Graphite is soft and easy to remove from sliding surfaces. The Raman peaks at 794 and 970 are due to exposed SiC material. As is clear from Fig. 11, the Raman spectrum of DLC tested at $300^{\circ} \mathrm{C}$ is similar to that of virgin DLC, suggesting that this film is still stable at this temperature. Other investigators have also found that, at elevated temperatures, the DLC films lost their diamondlike character and become more graphitelike $[7,14,20]$. 


\section{SiC/Diamond-coated SiC Pairs}

As shown in Fig. 4, the friction coefficient of $\mathrm{SiC}$ pins against diamond films were significantly higher. We believe that these high friction coefficients are due primarily to the generally rough surface finish of these coatings (see Fig. 2). During successive sliding cycles, the gaps between asperities were partially filled with debris particles (see Fig. 10) and the summits of asperities were worn away, especially at elevated temperatures (see Fig. 12). As a result, a relatively smooth surface finish was eventually obtained. Therefore, the range of steady-state friction coefficients (0.25-0.5) shown in Fig. 4, is consistent with the increasingly smoother surface finish. Previous investigators have reported close correlation between surface roughness and friction coefficients of diamond films. In general, it was found that the higher the surface roughness the greater the friction coefficients. The friction coefficients reported in Fig. 4 are consistent with the results reported by these investigators [18,21-24,27].

As is clear from Fig. 11, the diamond films are not noticeably graphitized like the DLC films even after tests at $400^{\circ} \mathrm{C}$. The Raman band at $1332 \mathrm{~cm}^{-1}$ (characteristic of diamond) is still very sharp. However, the shouldered peak at around $1580 \mathrm{~cm}^{-1}$ becomes more prominent, perhaps suggesting minor graphitization in this film as well.

\section{DISCUSSION-WEAR}

\section{SiC/SiC Test Pairs}

An overview of the wear mechanisms of $\mathrm{SiC}$ ceramics suggests that microfracture [31] and tribochemical [32] interactions have significant effects on the wear behavior of SiC. Electron microscopy of the wear scars and tracks of $\mathrm{SiC}$ pins and flats revealed large-scale brittle fracture, as well as some grain pullouts (Fig. 8). Therefore, we believe that intra- and/or inter-granular fracture was the dominant wear mechanism for $\mathrm{SiC}$ test pairs. 
Wear due to tribochemical interactions, especially at higher temperatures, is very likely, but the physical evidence for this type of wear could not be verified in this study, presumably, the tribochemical films consisting of $\mathrm{C}$ and/or $\mathrm{O}$ were too thin to be detected with the Raman spectroscopy used in our study. The results of previous studies suggested the formation of such tribochemical films at elevated temperatures and showed correlation of the lower wear and friction coefficients to the presence of such films at sliding interfaces [32]. The friction coefficients in our case were high at all temperatures further suggesting that there was not significant film formation at the sliding interfaces of $\mathrm{SiC} / \mathrm{SiC}$ test pairs.

\section{SiC/DLC-SiC Test Pairs}

The results from these pairs demonstrate that the DLC films can impart very low wear $\left(1.2 \times 10^{-8}\right.$ $\mathrm{mm}^{3} / \mathrm{N} . \mathrm{m}$ to $2.2 \times 10^{-8} \mathrm{~mm}^{3} / \mathrm{N} . \mathrm{m}$ ) to sliding $\mathrm{SiC}$ surfaces. We believe that the high mechanical hardness (i.e., $17 \mathrm{GPa}$ ) and low-friction coefficients (i.e., 0.2 ) of these films were largely responsible for the low wear rates of pins and flats at temperatures up to $300^{\circ} \mathrm{C}$. We attribute the significantly higher wear rates at $400^{\circ} \mathrm{C}$ to the removal of DLC films from the substrate surfaces (see Fig. 5). The Raman spectrum of film tested at $400^{\circ} \mathrm{C}$ revealed that the remaining film turned into graphite, suggesting that the practical uses of DLC films should be confined to temperatures of $<300^{\circ} \mathrm{C}$.

\section{SiC/Diamond-Coated SiC}

Electron microscopy examination of the wear tracks of diamond-coated flats indicates that these films remained intact on the sliding surfaces (see Figs. 9, 10) even at $400^{\circ} \mathrm{C}$, although they underwent some polishing and/or smoothening during repeated sliding (see Fig. 12). Moreover, Fig. 10 reveals that some debris particles had transferred from the pin side and filled in the valleys between diamond asperities. Based on these observations, we can conclude that diamond films effectively protected underlying substrates against wear even at the highest test temperature of 
$400^{\circ} \mathrm{C}$. However, because of their extreme hardness and rough surface finish, the diamond films caused substantial wear on the relatively softer counterface pins. This observation is consistent with the results of Haywood and of Kozakhi et al. who also reported high wear rates for rough diamond films at room and elevated temperatures.

\section{CONCLUSIONS}

Based on the results reported above, we can conclude the following:

(1) Under the test conditions of this study, sliding of $\mathrm{SiC}$ on itself causes high friction and severe wear losses. Increasing the test temperature is detrimental to the wear behavior of $\mathrm{SiC}$ ceramics.

(2) Based on electron microscopy evidence, microfracture appeared to be the dominant cause of wear for sliding $\mathrm{SiC}$ pins and flats.

(3) Because of its smooth surface finish and low-friction character, DLC films reduced the wear rates of $\mathrm{SiC}$ pins by two to three orders of magnitude, depending on test temperature. At temperatures higher than $\approx 300^{\circ} \mathrm{C}$, they were graphitized and removed effectively from the sliding surfaces.

(4) Diamond films were able to endure much higher temperatures. However, because of a rough surface finish, friction and wear losses were substantial.

(5) In selecting diamond or DLC films for tribological applications, it is important to remember that the limited-temperature capability of DLC and rough surface finish of diamond films can pose serious problems. 


\section{ACKNOWLEDGMENTS}

The authors thank C. Zuiker of Argonne National Laboratory for performing the laser-Raman spectroscopy and P. Wilbur of Colorado State University for furnishing the DLC coatings. This work was supported by the U.S. Department of Energy, under Contract W-31-109-Eng-38.

\section{REFERENCES}

1. Braza, J. F. and Sudarshan, T. S., "Tribological Behavior of Diamond and Diamondlike Carbon Films: Status and Prospects," in Surface Modification Technologies V(T. S. Sudarshan and J. F. Braza, eds.), The Institute of Materials (1992), pp. 801-819.

2. "Status and Applications of Diamond and Diamond-like Materials: An Emerging Technology," National Materials Advisory Board, Washington DC, (1990)

3.van Enckevort, W. J. P., "Diamond Coatings," J. Hard Mat., 1 pp. 247-272, (1990).

4. Ajayi,O. O., Erdemir, A.,Fenske, G. R., Nichols, F. A., Sproul, W. D., Graham, M., and Rudnik, P. J., "Tribological Behavior of Oil-Lubricated TiN-Coated Steel," Surf. Coat. Technol., 54/55, pp. 496-501, (1992).

5.Roth, T. H., Broszeit, E., and Kloos, K. H, Surf. Coat. Technol., "Influence of Elastohydrodynamic Conditions in Highly Loaded Lubricated Contacts on the Wear Behavior of TiN Coatings Prepared by R.F. Bias Sputtering," 36 pp. 765-772 (1988).

6. Erdemir, A., Nichols, F. A., Pan, X. Z., Wei, R., and Wilbur, P., "Friction and Wear Performance of Ion-beam-deposited Diamondlike Carbon Films on Steel Substrates, "Diamond and Rel. Mat., 3, pp. 119-125 (1993).

7. Erdemir, A., Bindal, C., Fenske, G. R., and Wilbur, P., "Tribological properties of hard carbon films on zirconia ceramics,"Tribol. Trans., in press, 1995

8. Zuiker, C., Krauss, A. R., Gruen, D. M., Pan, X., Li, J. C., Csencsits, R., Erdemir, A., Bindal, C., and Fenske, G. R., "Physical Properties of Diamond Films Grown in Argon-carbon Plasmas," Thin Solid Films, in press, 1995

9. Meletis, E. I., Erdemir, A., and Fenske, G. R., "Tribological Characteristics of

Duplex/Diffusion Coating Plasma Treatments," Sirf. Coat. Technol., in press, 1995 
10. Wei, R., Wilbur, P. J., Erdemir, A., Kustas, F. M., "The Effects of Beam Energy and Substrate Temperature on the Tribological Properties of Hard-carbon Films on Alumina," Surf. Coat. Technol., 51, pp. 139-145 (1992).

11. Erdemir, A., Switala, M., Wei, R., and Wilbur, P., "A Tribological Investigation of the Graphite-to-Diamondlike Behavior of Amorphous Carbon Films Ion Beam Deposited on Ceramic Substrates," Surf. Coat. Technol., 50, pp. 17-23 (1991).

12. Erdemir, A., Bindal, C., Fenske, G. R., Zuiker, C., Krauss, A. R., and Gruen, D. M., "Friction and Wear Properties of Smooth Diamond Films Grown in Fullerene-argon Plasmas," Diamond and Related Materials, In press, 1995

13. Enke, K., Dimigen, $\mathrm{H}$., and Hubsch, $\mathrm{H}$., "Frictional Properties of Diamondlike Carbon Layers," Appl. Phys. Lett., 36, pp. 291-292 (1980).

14. Miyoshi, K., Pouch, J. J., and Alterovitz, S. A., "Plasma-Deposited Amorphous Hydrogenated Carbon Films and Their Tribological Properties," Mater. Sci. Forum, 52/53, pp. 645-656 (1989).

15. Gardos, M. N., and Soriano, B. L., "The Effect of Environment on the Tribological Properties of Polycrystalline Diamond Films," J. Mater. Res., 5, pp. 2599-2609 (1990).

16. Miyoshi, K., Wu, R. L. C., Garscadden, A., Friction and wear of diamond and diamondlike carbon coatings, Surf. Coat. Technol., 54/55, pp. 428-434 (1992).

17. Hayward, I. P., "Effect of roughness on the friction of diamond on CVD diamond coatings" Wear, 157, pp. 215-227 (1992)

18. Hayward, I. P., "Friction and Wear Properties of Diamonds and Diamond Coatings," Surf. Coat. Technol., 49 pp. 554-559 (1991).

19. Hayward, I. P., Singer, I. L., and Seitzman, L. E., "Effect of Roughness on the Friction of Diamond on CVD Diamond Coatings," Wear, 157, pp. 215-227 (1992).

20. Grill, A., Patel, V., and Meyerson, B., "Tribological Behaviour of Diamond-Like Carbon: Effects of Preparation Conditions and Annealing," Surf. Coat. Technol., 49, pp. 530-536 (1991).

21. Kohzaki, M, Higuchi, K., Noda, S., Uchida, K., Tribological characteristics of polycrystalline diamond films produced by chemical vapor deposition, J. Mater. Res. 7, pp. 1769-1777 (1992).

22. Dugger, M., T., Peebles, D. E., and Pope, L. E., "Counterface Material and Ambient Atmosphere: Role in the Tribological Performance of Diamond Films,"in Surface Science Investigations in Tribology, Experimental Approaches, (Y.-W. Chung, A. M. Homolo, and G. B. Street, ACS Symposium Series 485, American Chemical Society, Washington D.C., (1992), pp. 
$72-102$.

23. Gardos, M. N., and Ravi, K. V., Surface Chemistry Controlled friction and Wear Behavior of Si (100) vs Textured Polycrystalline Diamond Film Tribocontacts, Diamond Films and Technology, 4, pp.139-165 (1994).

24. Gardos, M. N., Tribology and Wear Behavior of Diamond, in Synthetic Diamond (K. E. Spear and J. P. Dismukes, eds.) The Electrochemical Society Series, John Wiley \& Sons, Inc., New York, (1994) pp. 419-503.

25. Material Data Sheet, Kyocera International, Inc., 8611 Balboa Ave, San Diego, CA 92123.

26. 1990 Annual Book of ASTM Standards, Vol. 3., Wear and Erosion; Metal Corrosion, G9990, "Standard Test Method for Wear Testing with a Pin-On-Disk Apparatus," ASTM, Philadelphia, PA (1990), pp. 391-395.

27 Miyoshi, K., Wu, R. L. C., Arscadden, A., Barnes, N., Jackson, L., Friction and Wear of Plasma-Deposited Diamond Films, J. Appl. Phys., 74, pp. 4446-4454 (1993).

28. Knight, D. S., and White, W. B., "Characterization of Diamond Films by Raman Spectroscopy," J. Mater. Res., 4, pp. 385-393 (1989).

29. Cooper, C.V., Beetz, C. P., Buchholtz, B. W., Wilbur, P., and Wei, R., "Spectroscopic and Selected Mechanical Properties of Diamond-Like Carbon Films Synthesized by Broad-Beam Ion Deposition From Methané", Surf. Coat. Technol., 68/69, pp. 534-541 (1994).

30. Tamor, M. A., and Vassell, W. C., "Raman "Fingerprinting"of Amorphous Carbon Films", J. Appl. Phys., 76, pp. 3823-3830 (1994).

31. Ajayi, O. O., and Ludema, K. C., "Surface Damage of Structural Ceramics: Implications for Wear Modelling," Proc. Conf. Wear of Materials, (Ludema, K. C., Ed.), American Society of Mechanical Engineers, New York, (1987), pp. 349-360.

32. Miyoshi, K., Buckley, D. H., and Srinivasan, M., "Tribological Properties of Sintered Polycrystalline and Single-Crystal Silicon Carbide,"Ceramic Bulletin, 62, 4, pp. 494-500. 


\section{FIGURE CAPTIONS:}

Figure 1. Cross-sectional SEM photomicrographs of (a) DLC (b) diamond films used in this study.

Figure 2. Plan-view SEM photomicrograph of diamond film.

Figure 3.Laser Raman spectra of DLC and diamond films.

Figure 4. Friction coefficients of $\mathrm{SiC}$ pins against uncoated, DLC, and diamond-coated $\mathrm{SiC}$ flats at temperatures up to $400^{\circ} \mathrm{C}$ (test conditions: load, $10 \mathrm{~N}$; speed, $0.05 \mathrm{~m} / \mathrm{s}$; sliding distance, $200 \mathrm{~m}$; relative humidity, $30 \%$ ).

Figure 5. SEM photomicrograph of wear track formed on DLC-coated SiC flat during test at $400^{\circ} \mathrm{C}$. (test conditions: load, $10 \mathrm{~N}$; speed, $0.05 \mathrm{~m} / \mathrm{s}$, relative humidity, $30 \%$; sliding distance, 200 $\mathrm{m})$.

Figure 6. Average wear rates of $\mathrm{SiC}$ pins during sliding against uncoated, DLC, and diamondcoated $\mathrm{SiC}$ flats at temperatures up to $400^{\circ} \mathrm{C}$ (test conditions: load, $10 \mathrm{~N}$; speed, $0.05 \mathrm{~m} / \mathrm{s}$; sliding distance, $200 \mathrm{~m}$; relative humidity, $30 \%$ ).

Fig. 7. SEM photomicrographs of wear scars formed on $\mathrm{SiC}$ pins during sliding against (a) uncoated, (b) DLC-coated and $\mathrm{C}$ diamond-coated $\mathrm{SiC}$ flats (test conditions: load, $5 \mathrm{~N}$; speed, $0.05 \mathrm{~m} / \mathrm{s}$, sliding distance, $200 \mathrm{~m}$; relative humidity, $30 \%$; temperature, $23^{\circ} \mathrm{C}$ ).

Fig. 8. SEM photomicrograph of worn surfaces of $\mathrm{SiC}$ flat formed during tests at $100^{\circ} \mathrm{C}$.

Figure 9. 3-D surface maps of wear tracks formed on (a) uncoated, (b) DLC-coated, and (c) diamond-coated $\mathrm{SiC}$ flat (test conditions: load, $10 \mathrm{~N}$; sliding velocity, $0.05 \mathrm{~m} / \mathrm{s}$; relative humidity, $20 \%$; sliding distance, $200 \mathrm{~m}$; temperature, $200^{\circ} \mathrm{C}$ ).

Fig. 10. SEM photomicrograph of worn surface of diamond-coated $\mathrm{SiC}$ flat formed during tests at $200^{\circ} \mathrm{C}$.

Fig. 11. Raman spectra of graphite and diamond and DLC films before and after tests at various temperatures.

Fig. 12. Fig. 10. SEM photomicrograph of worn surface of diamond-caoted $\mathrm{SiC}$ flat after test at $400^{\circ} \mathrm{C}$. 


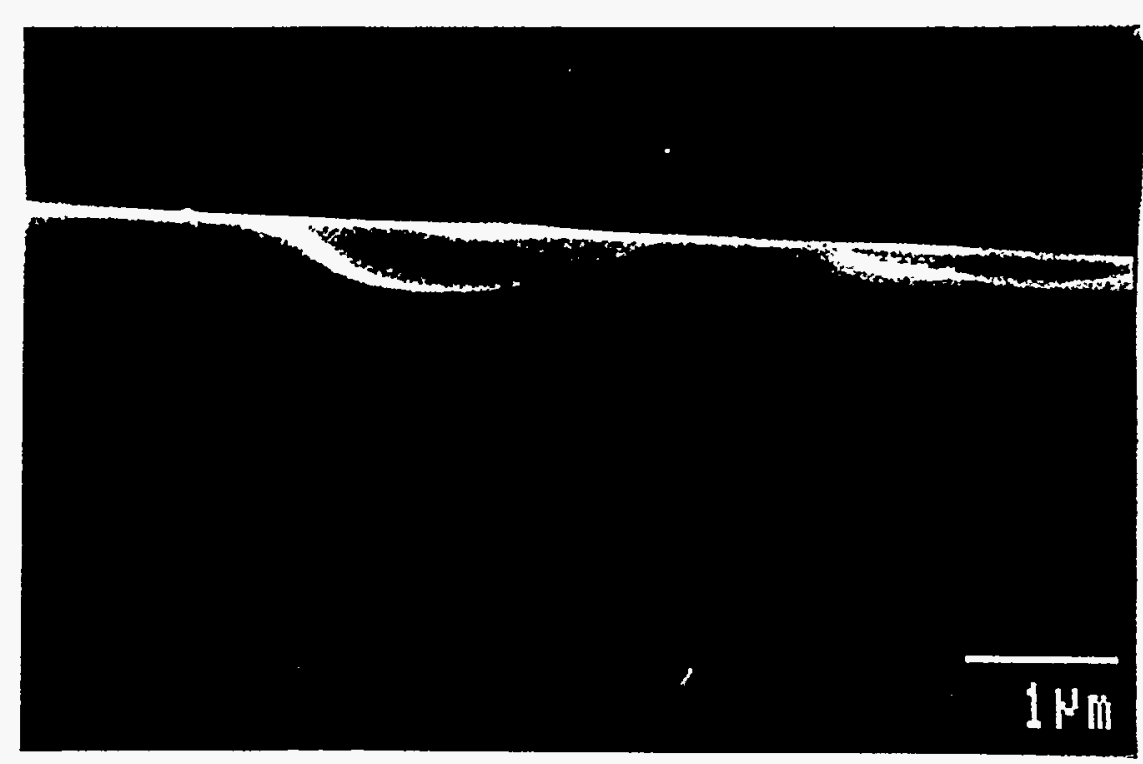

(a)

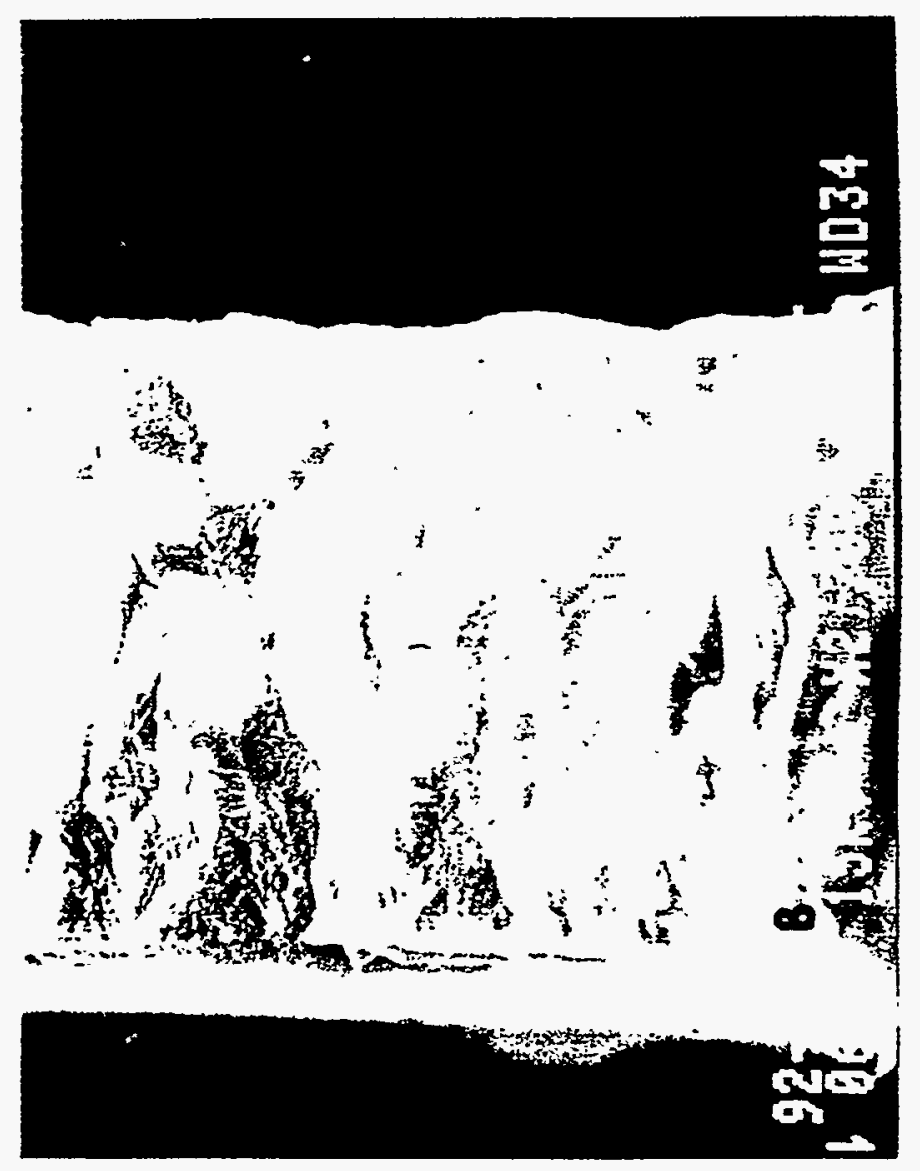

(b)

Figure 1. Cross-sectional SEM phun: 

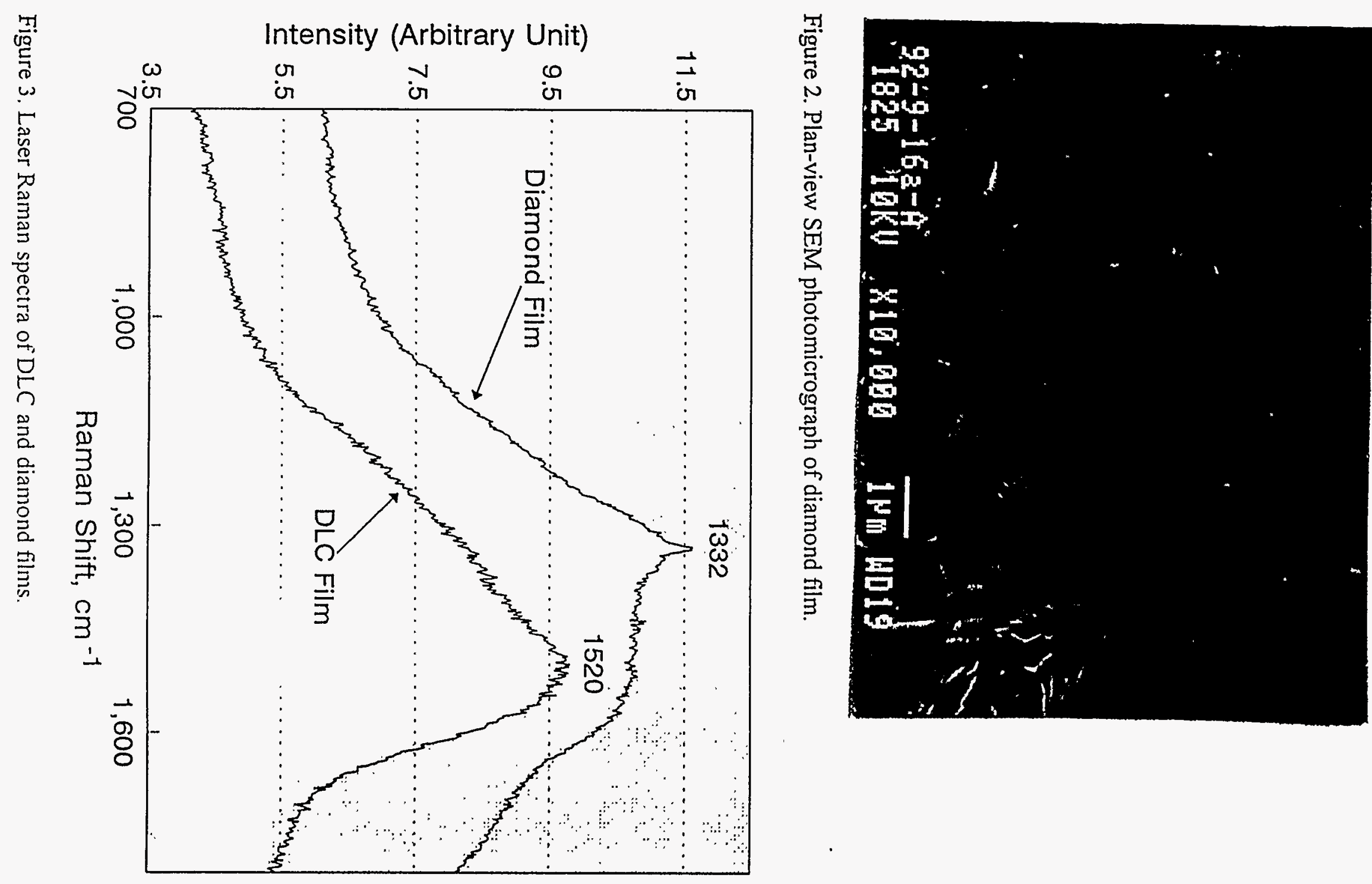


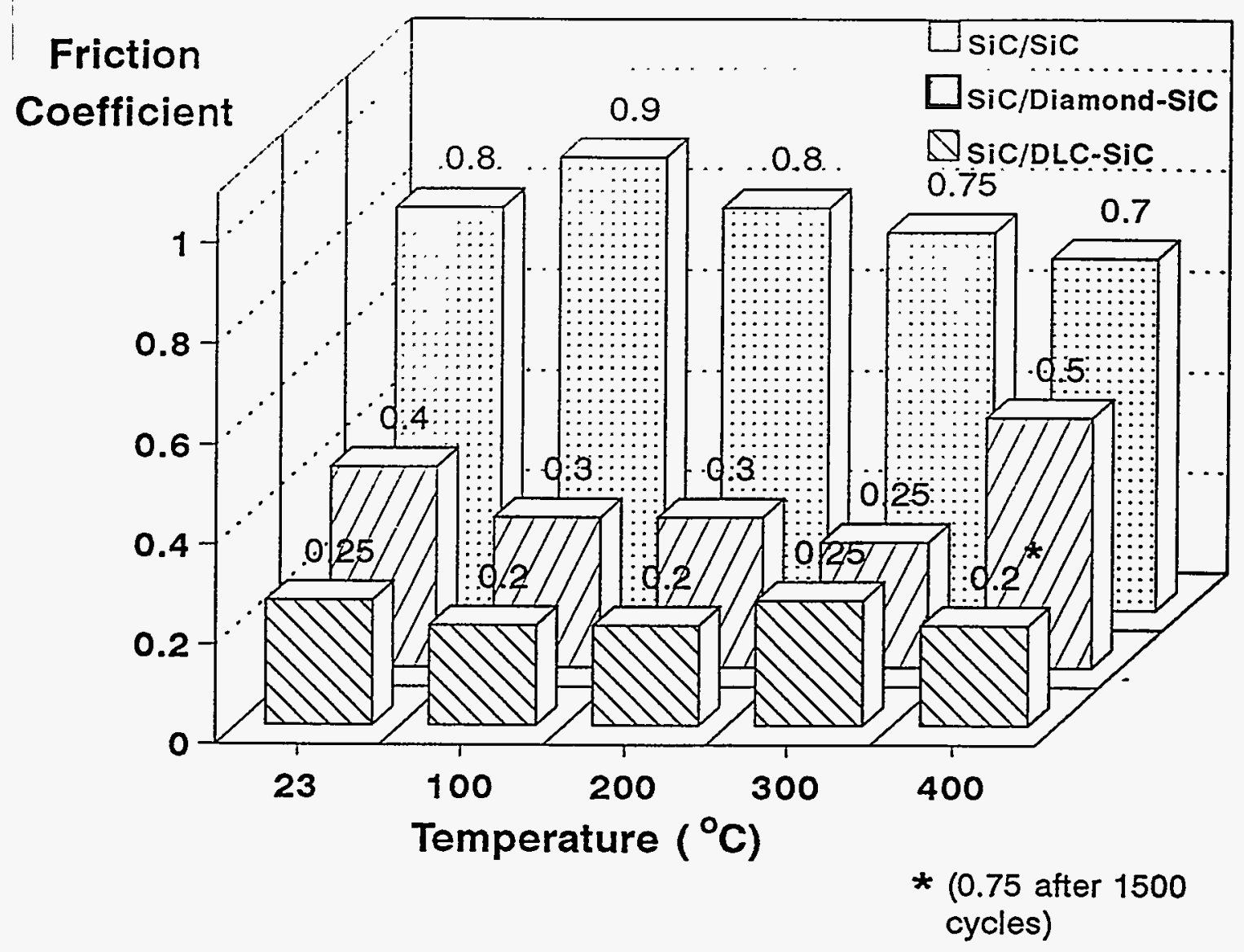

Figure 4. Friction coefficients of $\mathrm{SiC}$ pins against uncoated, DLC, and diamond-coated $\mathrm{SiC}$ flats at temperatures up to $400^{\circ} \mathrm{C}$ (test conditions: load, $10 \mathrm{~N}$; speed, $0.05 \mathrm{~m} / \mathrm{s}$; sliding distance, $200 \mathrm{~m}$; relative humidity, $30 \%$ ).

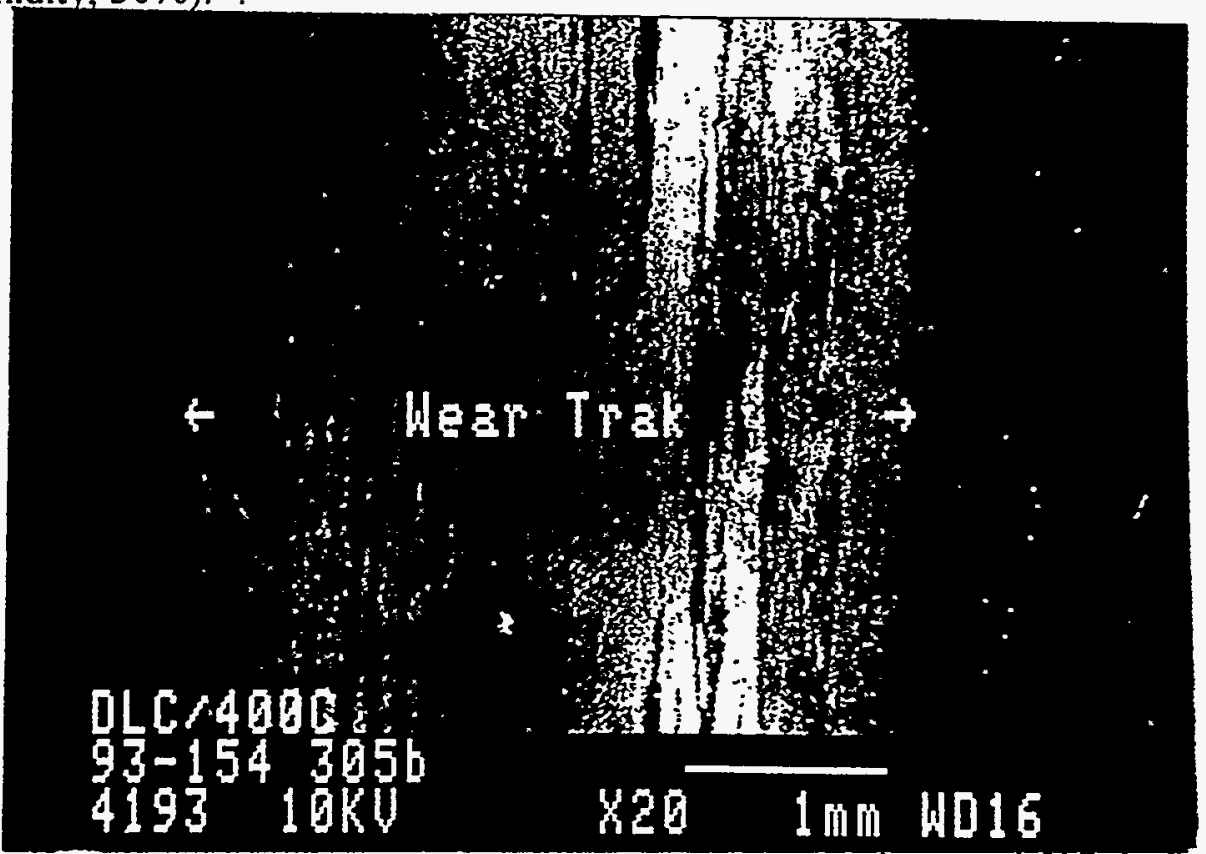

Figure 5. SEM photomicrograph of wear track formed on DLC-coated SiC during test at $400^{\circ} \mathrm{C}$. (test conditions: load, $10 \mathrm{~N}$ : speed. $005 \mathrm{~m} / \mathrm{s}$. relative humidity. $30^{\circ} \%$ : sliding distance, $200 \mathrm{~m}$ ). 


\section{Average}

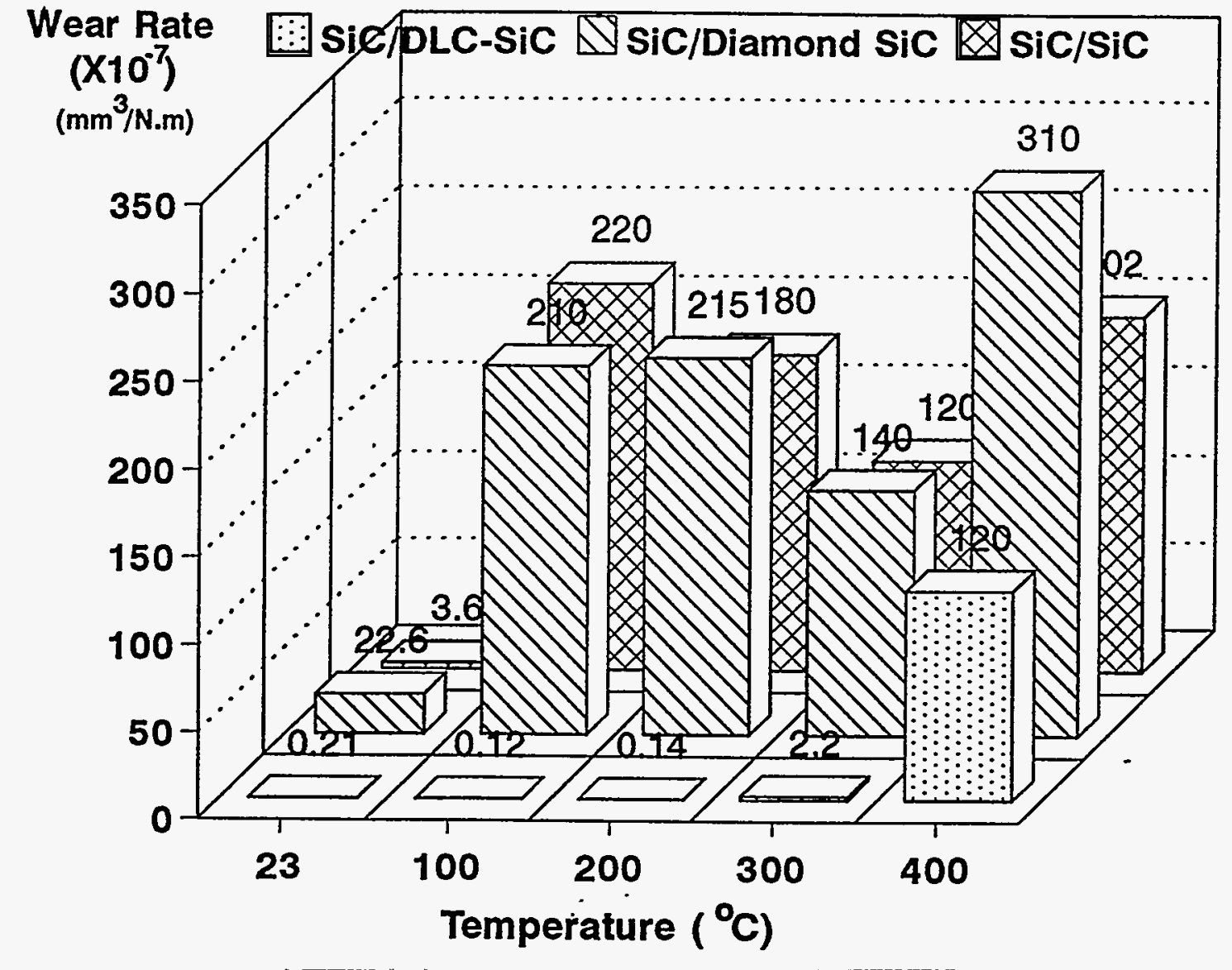

Figure 6. Average wear rates of $\mathrm{SiC}$ pins during sliding against uncoated, DLC, and diamondcoated $\mathrm{SiC}$ flats at temperatures up to $400^{\circ} \mathrm{C}$ (test conditions: load, $10 \mathrm{~N}$; speed, $0.05 \mathrm{~m} / \mathrm{s}$; sliding distance, $200 \mathrm{~m}$; relative humidity, $30 \%$ ). 


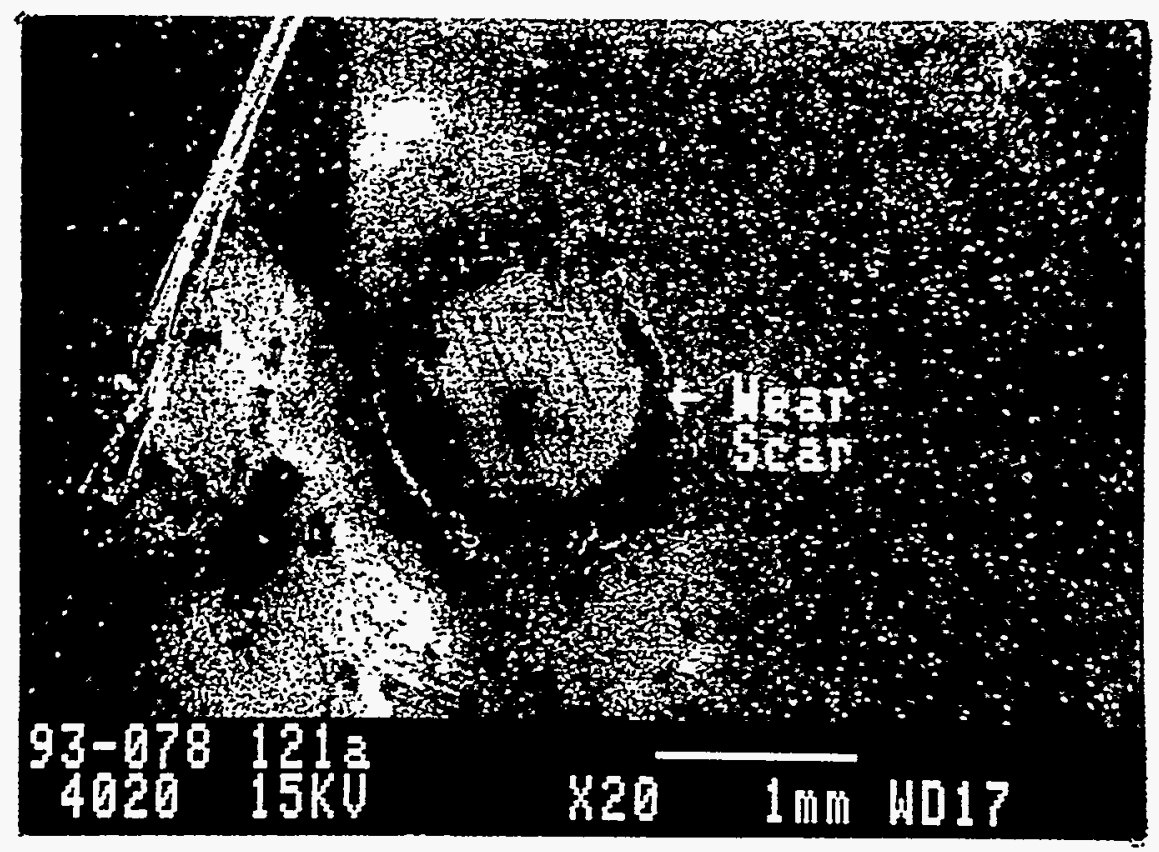

(a)

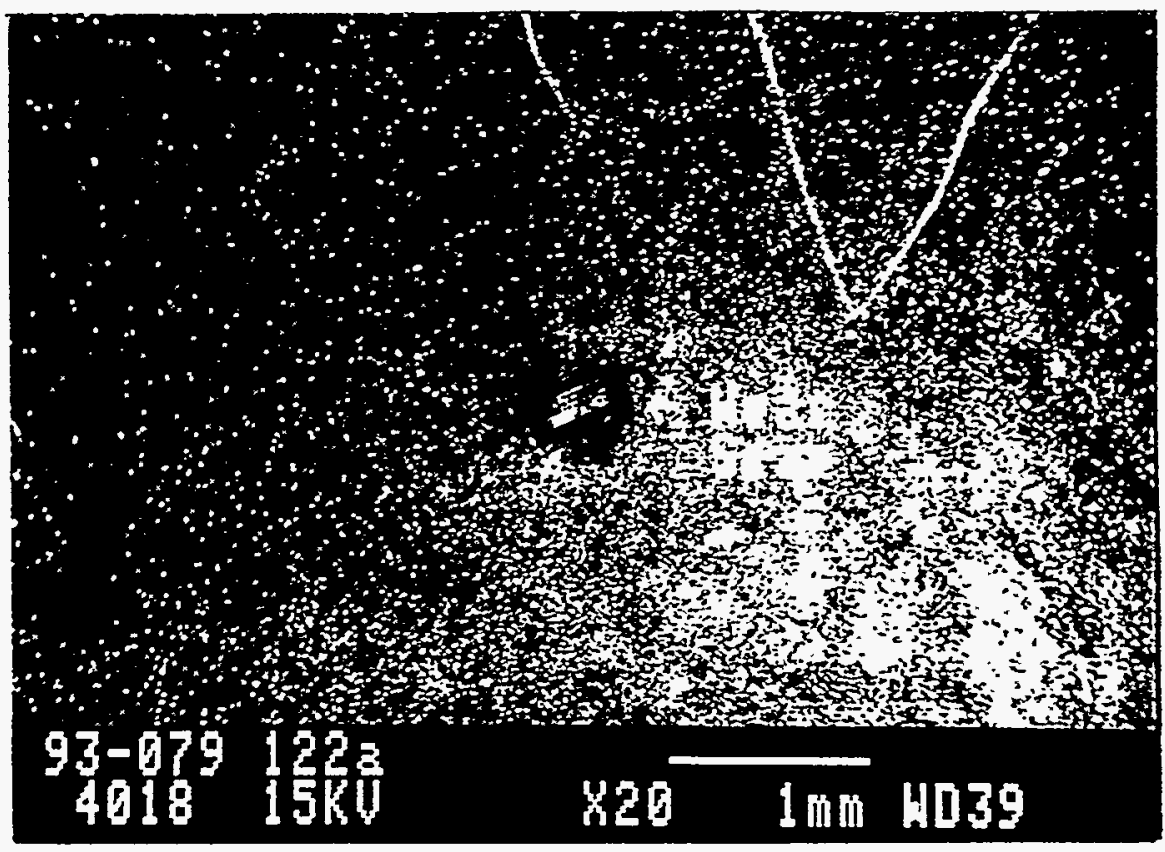




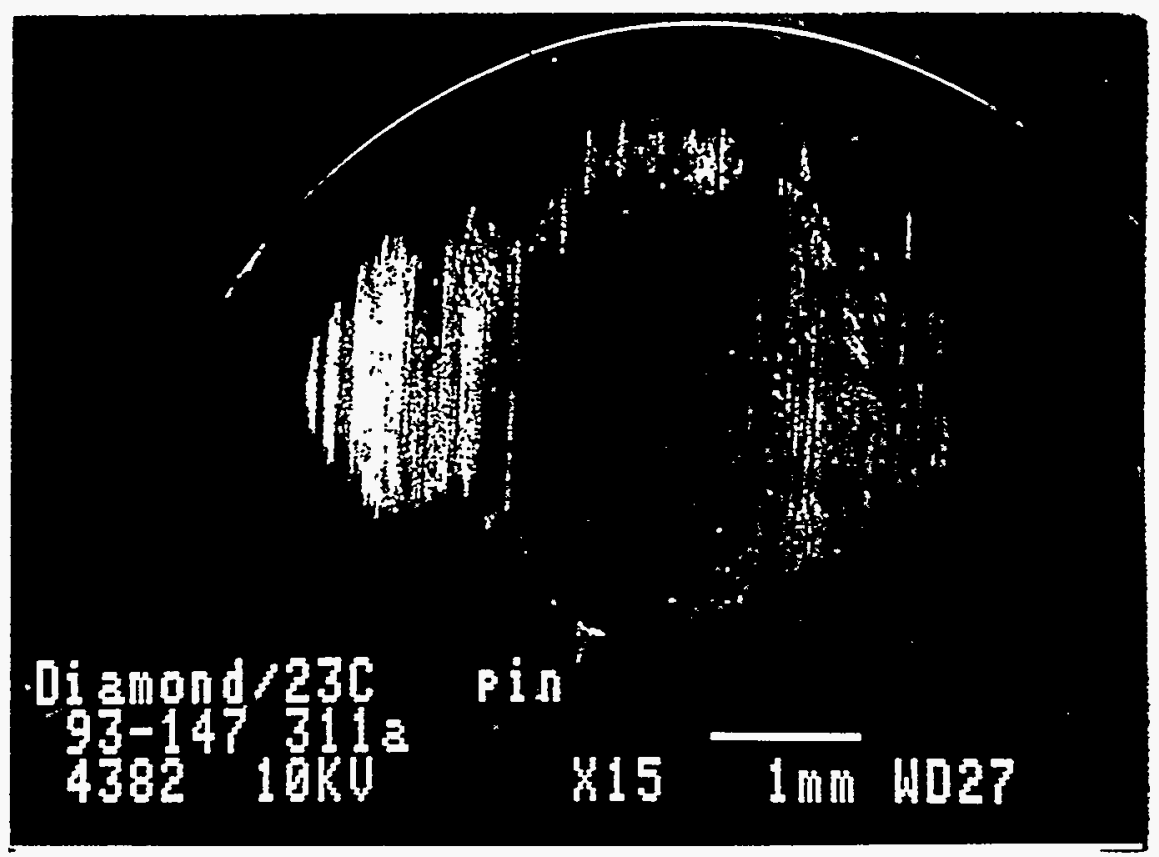

(c)

Fig. 7. SEM photomicrographs of wear scars formed on SiC pins during sliding against (a) uncoated, (b) DLC-coated and (c) diamond-coated SiC flats (test conditions: load, $5 \mathrm{~N}$; speed, $0.05 \mathrm{~m} / \mathrm{s}$, sliding distance, $200 \mathrm{~m}$; relative humidity, $30 \%$; temperature, $23^{\circ} \mathrm{C}$ ).

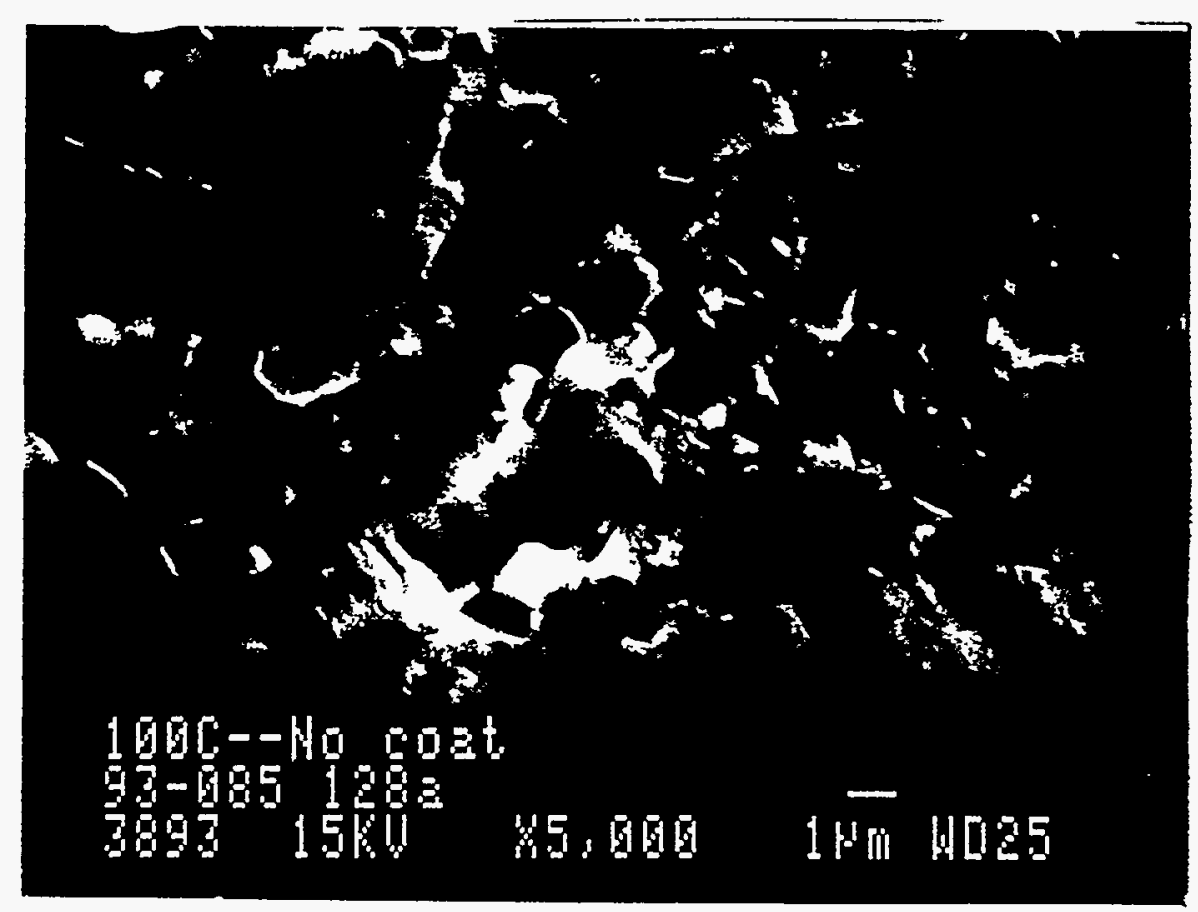

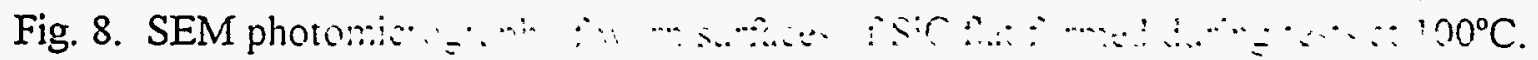




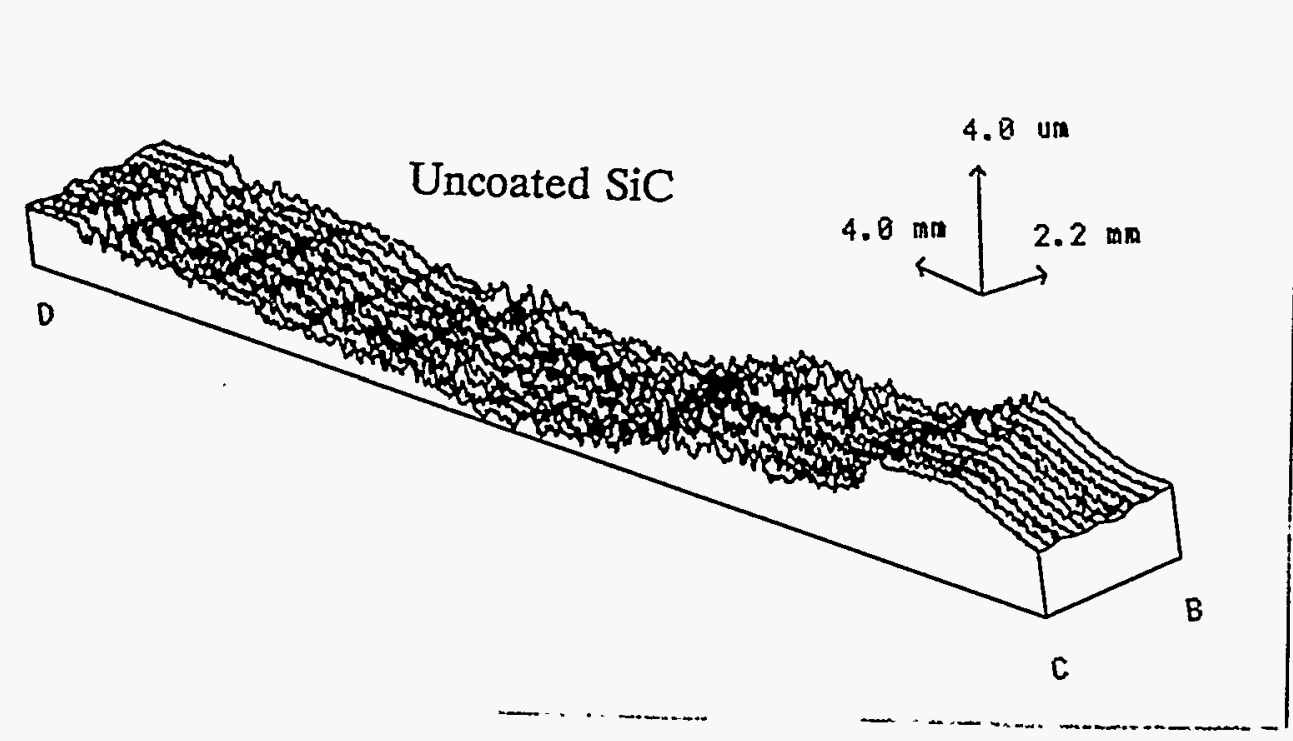

(a)

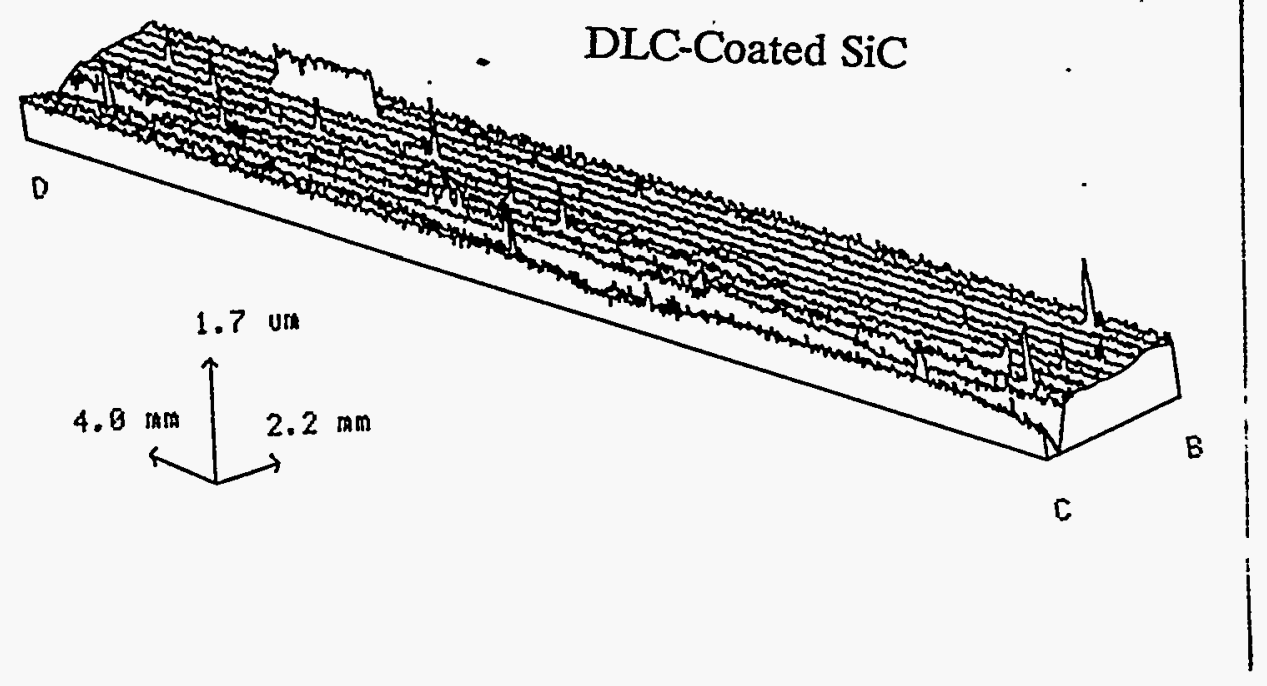

(b) 


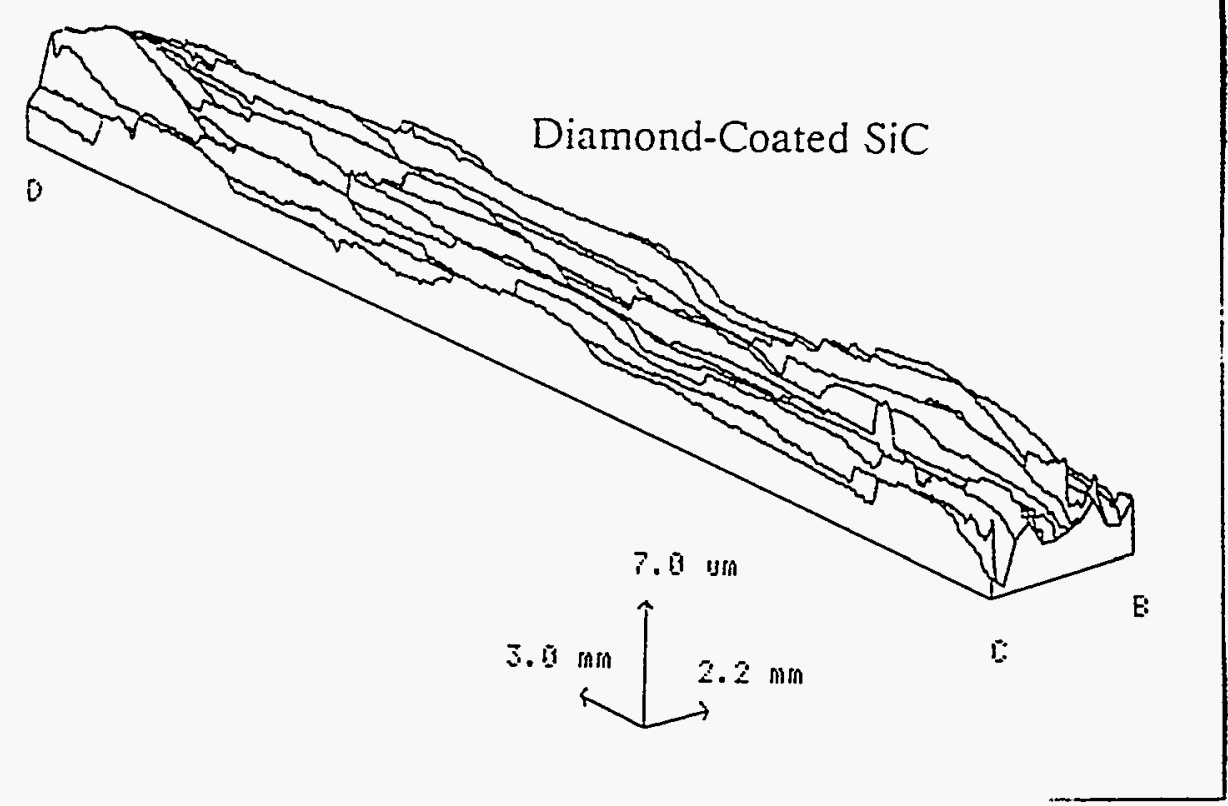

(c)

Figure 9. 3-D surface maps of wear tracks formed on (a) uncoated, (b) DLC-coated, and (c) diamond-coated $\mathrm{SiC}$ flat (test conditions: load, $10 \mathrm{~N}$; sliding velocity, $0.05 \mathrm{~m} / \mathrm{s}$; relative humidity, $20 \%$; sliding distance, $200 \mathrm{~m}$; temperature, $200^{\circ} \mathrm{C}$ ).

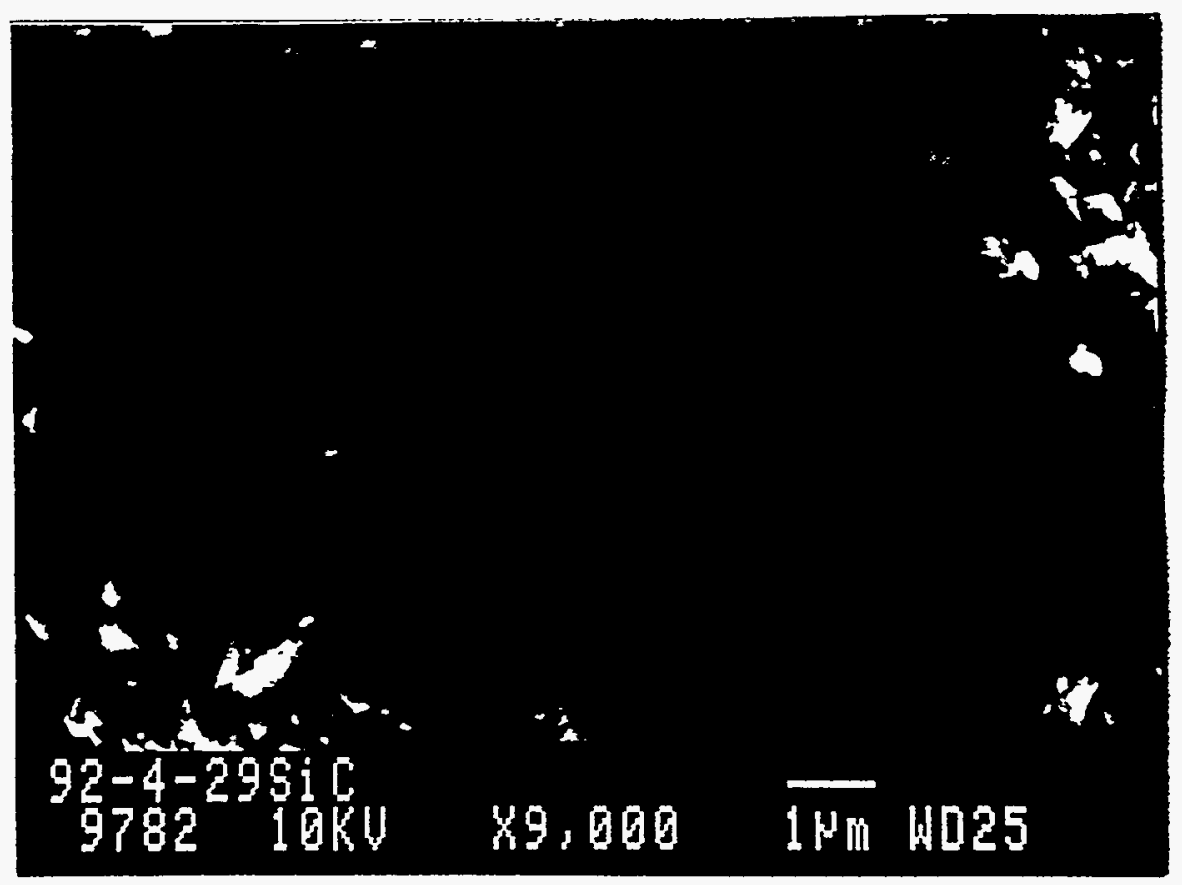

Fig. 10. SEM photomicrograph of worn surface of diamond-coated $\mathrm{SiC}$ flat formed during tests at $200^{\circ} \mathrm{C}$. 


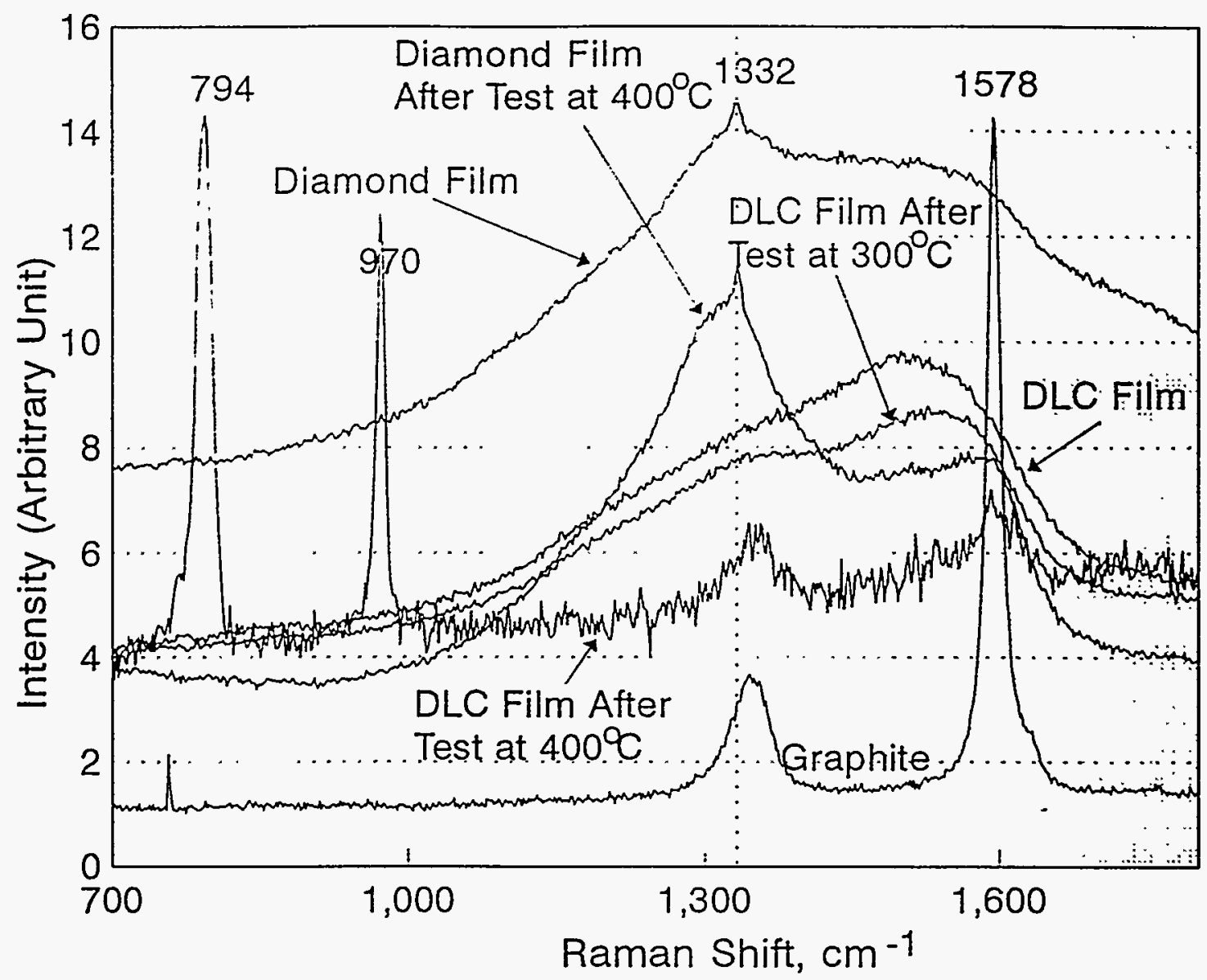

Fig. 11. Raman spectra of graphite and diamond and DLC films before and after tests at various temperatures.

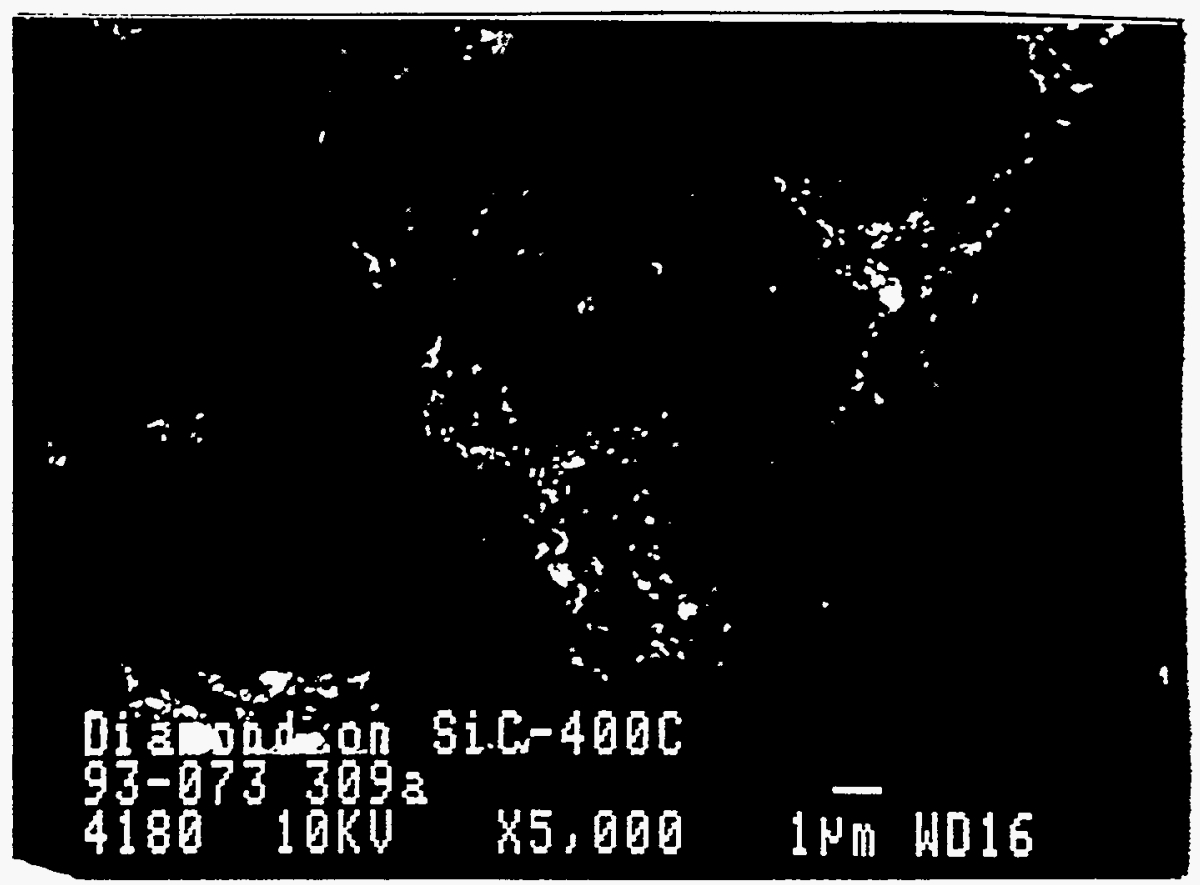

Fig. 12. SEM photomicrograph of worn surface of diamond-caoted SiC flat after test at $400^{\circ} \mathrm{C}$. 